\title{
Developing a Conceptual Framework for Considering the Complexities of Professional Learning and Development in the Secondary School Context
}

\author{
Dr Camilla Highfield*, Dr Jenny Robertson \\ The University of Auckland, Auckland, New Zealand \\ *Corresponding author: c.highfield@auckland.ac.nz
}

Received February 12, 2015; Revised April 15, 2015; Accepted April 28, 2015

\begin{abstract}
This paper discusses the development of a conceptual framework for scoping, provisioning and reporting the complexities of in-service Professional Learning and Development (PLD) in the New Zealand secondary school sector with a focus on middle leaders. Government-funded PLD in the New Zealand context is a research and evidence-based service provided to schools in response to high-level government policy. These PLD contracts aim to address inequalities for young people by enhancing the quality and effectiveness of leadership and teaching practices which result in increased student achievement, especially for priority students and those from minority backgrounds. The rationale for developing a conceptual framework for understanding government-funded, externally provided professional learning and development will be discussed. Recommendations for policy makers and researchers on the complex ways research evidence and policy come together in the delivery of in-service PLD for leaders and teachers in schools will be highlighted and opportunities for improvement examined.
\end{abstract}

Keywords: professional learning and development, middle leaders, secondary schools, schooling improvement

Cite This Article: Dr Camilla Highfield, and Dr Jenny Robertson, "Developing a Conceptual Framework for Considering the Complexities of Professional Learning and Development in the Secondary School Context." American Journal of Educational Research, vol. 3, no. 5 (2015): 610-618. doi: 10.12691/education-3-5-13.

\section{Introduction}

Researchers and academic practitioners produce literature (published as books, articles or guides) that bring together theory and evidence of effective (or 'best') practice related to educational leadership and teaching. However, it can be difficult to successfully implement these evidence-based understandings of effective practice in dysfunctional schooling contexts where there are often multiple and systemic layers of ineffective leadership. Alternatively, the challenge of implementing evidencebased best practice may be in the need to 'translate' material to align it with policy-level educational priorities, or to find a way to get it to 'fit' into the complex array of systems and practices, and the generally crowded space that is twenty-first century schooling.

PLD provision for schools to support leaders and teachers to develop best practiceis a research-informed process rather than a research-producing one. PLD initiatives are required to be evaluated in terms of process outcomes, and especially impact outcomes, as an indicator of PLD effectiveness. The provision of tailored PLD services, founded upon inquiry-based processes, draws upon multiple and diverse research findings brought together in unique ways. To help leaders and teachers to understand and use research evidence to inform and improve practice often means PLD facilitators adapt published materials to suit the classroom or school context where it is to be used. Facilitators of PLD are in a sense research brokers, providing a service that makes use of a range of relevant educational research and theory, and disseminating it in a form that makes it accessible and useable by the teachers and leaders intended to benefit from the research findings.

As externally provisioned government-funded PLD is evidence-based, it is clearly important for PLD practitioners to be able toshare their experiences with researchers. There are seldom opportunities in the New Zealand context where PLD providers are able to provide feedback to researchers on how well theoretical ideas have been able to be put into practice. We argue that structured and formalised opportunities for feedback to government and the broader education community to share ideas and results regarding which interventions had a positive impact are critical for on-going development of the education sector. Given the multiple, complex, and competing demands in the schooling improvement arena, and ideas about how research might need to be reshaped or reconceptualised in future, this feedback and feed forward will ensure the ongoing success of schooling intervention models. Furthermore, the provision of PLD often occurs in schooling contexts researchers have little access to, or knowledge of, or where ethical considerations make it difficult to access and collect data about what intervention strategies are successful - or not. Due to practical, ethical and privacy requirements, the 
important 'findings' from some types of PLD interventions often remain unreported beyond confidential contractual requirements.

This paper discusses the development of the framework in the context of the Secondary Student Achievement contract, a PLD project now in its third year that provides opportunities for curriculum level support through strengthening the instructional practices of middle leaders with a focus on raising student achievement. A coherent policy framework for school reform is critical in supporting ongoing improvement of the education system [3] but the extra impetus requires horizontal and lateral ways of working where instructional leadership practices are enhanced at all levels of the system. As teacher effectiveness is such an important factor in determining student achievement and attainment, the extent that teacher leadership can act as a catalyst for improving practice, changing beliefs and behaviours and positively impacting on effectiveness in the classroom [7] is central to the intervention. In the secondary school context it is the middle leaders that often have the strongest connection to the teaching in their department. The structural context of high schools means that these middle leaders are a relevant focus for professional learning and development aimed at identifying predictors of improved student academic outcomes. The knowledge and developing understanding of critical aspects of middle leadership practice that are supported through the Secondary Student Achievement PLD intervention can contribute to the exisitng research and theory in this area as well as drawing from it.

The discussion begins with a rationale for developing a conceptual framework and describes anoverview of schooling improvement, the New Zealand secondary school sector, the secondary school qualifications system, and government priorities for education in New Zealand. The following section describes the PLD context in New Zealand and the government-funded Secondary Student Achievement (SSA) PLD contract. The delivery of this contract by the University of Auckland over three years has provided the platform for the development ofthe conceptual framework - the 'sandwich model' -which conceptualises the complexities of PLD in the secondary school sector. The presentation and explanation of the conceptual framework is followed by recommendations for policy makers and researchers.

\subsection{Why Develop a Conceptual Framework for Considering the Complexities of Professional Learning and Development?}

In-service professional learning and development for educational leaders and teachers is a recurrent feature of schooling improvement or school reform initiatives around the world. Whether it is PLD that is facilitated face-to-face in workshops and seminar presentations, intensive and individualised support provided in schools, or PLD for a broader audience using digital technologies and the internet, on-going professional learning is an integral part of the twenty-first century schooling improvement landscape. A coherent policy framework for school reform is critical for supporting ongoing improvement of the education system [3] but the extra impetus requires horizontal and lateral ways of working where instructional leadership practices are enhanced at all levels of the system. As teacher effectiveness is such an important factor in determining student achievement and attainment, the extent that teacher leadership can act as a catalyst for improving practice, changing beliefs and behaviours and increasing effectiveness in the classroom is central to the argument [7]. In the secondary school context it is the middle leaders who often have the strongest connection to the teaching in their department and this is where the focus of this PLD work is leveraged.

The environment within which government-funded secondary school PLD is delivered is complex and challenging. Like many OECD countries New Zealand secondary schools vary greatly between large urban settings with students from multiple ethnicities to small rural schools in remote locations. The PLD providers need to take account of a range of factors including sector-wide and individual school needs, government priorities, policies and goals, the availability of resources, reporting requirements and changes in technology. Developing a conceptual framework that explains this complexity can assist with effective planning, provisioning and implementation of PLD and subsequent reporting of outcomes. In addition, such a framework can be shared with other PLD providers in the interests of strengthening PLD provision across the sector and can be used to inform and structure recommendations for policy makers, researchers and the secondary sector.

The proposed framework will assist in bridging the gap between middle leadership practice and research in this field. The evidence-based nature of this PLD is discussed and provides the opportunity for sharing findings with researchers. The conceptual framework developed as a result of the Secondary Student Achievement PLD can add to the evidence base needed to inform future PLD provision focussed on middle leaders in secondary schools working more effectively to raise student achievement.

\subsection{Schooling Improvement}

The new millennium has seen a noticeable shift toward a greater public focus on student outcomes and increased accountability of schools, particularly in economically developed countries. The need for a competitive edge in the global economy, the changing skill requirements of technologically-based work places, the demand for citizens who can cope with the challenges of environmental change and degradation, and population diversity, are all strong drivers for increased performance of the public school system [11]. League tables that rank schools, websites where students can comment on their teachers' performance and publicly available evaluation reports carried out by government agencies(such as the New Zealand Education Review Office) have all put school leaders and teachers under increased pressure to ensure that their school is performing at or above expectation. Not only do teachers and leaders of schools compare their school results to each other and against nationally expected targets, but policy makers and researchers are comparing country level 'systems' and their ability to ensure students are performing at expectation, particularly in reading, writing and mathematics and science. The central challenge is to strengthen and maintain public confidence in a state-run 
education system for all so that people continue to send their children to public schools and provide their tax money for those schools to improve and develop [11]. When the majority of a country's citizens support their local state school, as is the case in New Zealand, there is a greater chance of an equitable school system.

During the last two decades a considerable body of evidence has accumulated to show that although the ability and socioeconomic background of students are a major determinant of achievement, schools can make a difference to students' levels of progress. School effectiveness research focuses on the achievement of all students and their progress over time. An effective school is one that adds value to student outcomes in comparison with other schools serving similar intakes [23]. At the secondary school level, much of the research to date has focussed on the organisation of effective secondary schools [10] and to some extent effective teaching within those schools. Much of this research highlights the fact that major sources of inequity lie within schools as well as between them. Decisions made within schools have been found to create substantial variability in teachers' conditions of work and students' opportunities to learn, even within the same school [10]. Reference [23] argues that effective schools are learning organisations, with teachers and leaders continuing to be learners, keeping up to date with their subjects and with advances in understanding about effective practice. The indirect empowerment of teachers by leaders when they create the conditions or provide the resources that directly impact on positive student outcomes is particularly relevant in the context of a secondary school department [22]. Reference [10] states that academic organisation in the high school system is a critical influence on students' academic outcomes and that effective school personnel understand the relationship between social relations, teaching and instruction, and academic learning. When department staff are instructionally led and focussed on high standards of student achievement, learners will reap the rewards.

\subsection{The New Zealand Secondary School Context}

New Zealand secondary schools are structured like many others in western countries where curriculum subjects are taught by a team of teachers organised into departments. In New Zealand secondary schools the eight essential learning areas in The New Zealand Curriculum [14] - Arts, English, Health and Physical Education, Learning Languages, Mathematics and Statistics, Social Sciences, Science, and Technology - are often used for organisational purposes. Secondary schools are generally divided into departments related to the curriculum learning areas, and the staff within them are usually led by a head of department. Other designated leaders have accountability for subjects within the learning area such as Head of Biology or a year level such as Head of Junior English.

\subsection{The New Zealand Curriculum (NZC)}

The New Zealand Curriculum [14] is the national curriculum that provides the direction for teaching and learning in New Zealand schools. It takes a nonprescriptive approach and requires schools to develop their own school-based curriculum in consideration of the needs of students and community. It encompasses a broader vision, principles and values for education and all learning is expected to contribute to these. This curriculum document also includes a framework for effective pedagogy to which the New Zealand Registered Teacher Criteria [25], the required professional standards for teachers, are closely aligned. Key competencies, or behaviours for learning, which are required to be developed across all year levels and within learning areas are described. Central to effective pedagogy is the notion of teaching as inquiry [14] which requires all teachers to use a continuous inquiry (and evidence) based approach to all programme design, planning and teaching decisions, and to track and monitor student progress toward, and achievement of, learning goals. Learning area (and subject) knowledge is framed by big ideas or concepts drawn from relevant bodies of disciplinary knowledge. The 'essence' of the learning areas is captured in a short description of the unique contribution each will make to a student's learning, and the ways this learning is expected to develop and progress is expanded in the Achievement Objectives over eight developmental levels, covering years 1-13.

\subsection{The New Zealand Secondary School Qualifications System}

The compulsory national qualifications system for state-funded secondary schools in New Zealand is called the National Certificate of Educational Achievement or NCEA which is managed by the New Zealand Qualifications Authority (NZQA). It is a standards-based assessment of student learning designed to provide three levels of national qualification for students studying subjects based on The New Zealand Curriculum taught nationally at secondary level. The Ministry of Education is the government department responsible for the development of achievement standards. The qualification is recognised by employers and used for selection by universities and polytechnics, both in New Zealand and overseas. Studentsaim to complete NCEA Levels 1-3 in successive years (including University Entrance at Level 3), typically in Years 11-13 (15-18 year olds).However, individual education plans that meet students' unique learning and qualifications pathways may mean NCEA levels are achieved in a diverse range of ways.

Unlike the norm-referenced and scaled examinations of the previous system (that ended just after the start of the new millennium), standards-based assessment does not focus on comparisons between students but on how well they perform in relation to the standard expected at each level. This system offers opportunities for students to be assessed through a combination of external subject-specific national examinations held at the end of the school year, and internal assessments administered by their teacher throughout the year. NZQA manages national moderation and quality assurance systems for internal assessments as well as the development and administration of examinations. Schools are expected to have local quality assurance systems for internal moderation established within and between subject department and interschool moderation and formal quality assurance processes to ensure that the assessment of each standard is fair across all students, regardless of the school they attend. 


\subsection{Government Priorities for Education in New Zealand}

The New Zealand system can be characterised at secondary level as one of high performance and low equity [13], with Māori and Pasifika students overrepresented in the statistics for students performing below expectations. Underpinning the PLD contract described in this paper are the current government's Better Public Service goals [15] which describe the goals for a high level cross-sector approach to create a public sector that can respond more effectively to the needs and expectations of New Zealanders. The Government has committed the public sector to achieving these targets in the next three to five years. The targets cover five themes, one of which is 'boosting skills and employment'. Under 'boosting skills and employment' the Ministry of Education as the lead agency has two targets:

1. 85 percent of 18-year-olds achieving NCEA level 2 or an equivalent qualification in 2017;

2. 55 per cent of 25-34 year olds will achieve a qualification at level 4 or above in 2017 (noting that access to these qualification pathways is largely contingent upon success at Levels 2 and 3).

The justification for target 1 is that NCEA level 2 "gives people the skills required for further education, to progress in working life, achieve better health outcomes and a better quality of life generally". For target 2, the justification is that "people with a level 4 and above qualification have higher incomes and a better economic return than those with lower qualifications” [15].

At present, these NCEA level 2 targets are typically being met by schools in higher socio-economic regions, and many low socio-economic status (SES) schools, particularly those with high Māori and Pasifika student populations, are still to meet these targets. A level 2 qualification is insufficient for University Entrance which can only be achieved at level 3 (17 and 18 year olds) and in accordance with a series of additional criteria. Student achievement of the successive levels of NCEA requires the design and delivery of high quality teaching and learning programmes that continue to meet individual student learning and qualification pathways needs across all years of schooling.

\section{SSA Professional Learning and Development}

\subsection{The Professional Learning and Development (PLD) Context}

The context that provided the opportunity for the development of this conceptual framework was the Secondary Student Achievement (SSA) contract funded though the New Zealand Ministry of Education. In response to current government priorities, the Ministry of Education provides a strategic selection of publicly funded PLD opportunities for selected schools. The provision of the PLD is contracted through a range of universities and private providers who specialise in this work. Schools with higher levels of student under-achievement, especially for priority learners (currently listed as being Māori, Pasifika, low socio-economic, Special Education
Needs (SEN) students, and students from low socioeconomic backgrounds) and as identified by Ministry of Education officials, have access to the most funded support for PLD.

Decisions about schools that receive this targeted PLD are based on school data that show student academic achievement, retention and suspension rates. Schools with comparatively poor statistics, particularly where the gap in achievement for minority and target students is not reducing, are targeted as requiring PLD support. The priority placed around achievement targets for Māori and Pasifika students is detailed more thoroughly in the policy and strategy statements Ka Hikitia - Accelerating Success 2013-2017 [18] and the Pasifika Education Plan 20132017 [19]. Students with Special Education Needs are also a schooling priority [17].

Currently in its third year, the SSA contract is delivered by two PLD providers in New Zealand. The NorthernCentral North contract is held by the University of Auckland (the developer of this paper and conceptual framework), and the remainder of the country is covered by a consortium of PLD providers and universities. Two thirds of the secondary schools in New Zealand are in the Northern-Central North region (geographically one quarter of the country). Represented among these schools are some of the most affluent and poorest regions in the country, as well as the most culturally diverse schools and, critically, the regions where the largest proportions of New Zealand's indigenous population (New Zealand Māori) live. The SSA contract is one of a few PLD initiatives specific to secondary schooling and the only one with specific learning area and subject support across the learning areas for senior secondary level.

PLD provided by the SSA contract is targeted at English-medium state-funded secondary school curriculum middle leaders in schools where data shows there are large proportions of priority learners at risk of not achieving. PLD outcomes to be reported include evidence of enhanced and effective middle leader practice that contribute to improved academic outcomes for students.

\subsection{Middle Leaders in New Zealand Secondary Schools}

Middle leaders include teachers with a designated leadership role in a curriculum area and teachers with responsibilities across learning areas e.g. academic or pastoral care deans, careers and guidance counsellors, specialist curriculum teachers (who support new teachers), and Māori or Pasifika liaison leaders. Most of these roles are accompanied by management units which provide additional salary and/or non-teaching time to fulfil the responsibilities of the role. New Zealand schools are selfgoverning and school Boards of Trustees are able to use available staff funding flexibly to create and assign leadership roles to a range of teachers which meet the needs of the school within government guidelines. Consequently, the nature of the roles and the titles given vary from school to school and large schools tend to have a very diverse range of middle leader roles. For the purposes of the SSA contract, the term 'middle leader' has been defined as those teachers with a designated leadership role in a curriculum area. Middle leaders in 
curriculum leadership roles have various titles including Head of Department (HOD), Head of Faculty (HOF), Head of Learning Area (HOLA) and Teacher in Charge.

PLD in New Zealand schools has been extensively informed by Teacher Professional Learning and Development: Best Evidence Synthesis [27]. The main findings of this extensive analysis of the teacher professional development research identifies evidence based teacher and leader practices that promote enhanced outcomes for students. The research shows that providing sufficient time for extended opportunities for teachers to engage with new knowledge that involved theoretical understandings, as well as engaging external expertise, has increased the effect size for student outcomes [27]. Schools that had the most sustained outcomes throughout and after a PLD intervention were those where school leaders actively led and engaged with the professional learning opportunities and were active participants in modelling their own professional learning for their staff [27].

\subsection{What is Effective Middle Leader Practice?}

The evidence suggests that there are clearly identifiable characteristics, attitudes, behaviours and beliefs of middle leaders in charge of successful departments [4,5,6,9,24]. These studies have linked specific dispositions and capacities to positive academic outcomes because when middle leaders make leadership decisions that have "students at the centre" [14] there is an inevitable impact on the quality of the teaching in the department. When the key leadership practices are missing at whole-school and department level or are dysfunctional, students are not so well served by their teachers. The specific practices employed by middle leaders to create the working conditions that motivate teachers in ways that impact positively on student outcomes are a critical focus for this PLD, and this paper describes which practices are being demonstrated in departments and how they link to improved student outcomes.

Research shows that as part of the professional learning culture of the school, leaders who provided targets for student outcomes and monitoring (whether these were met or not) were also successful [21], [27] and [12]. Leaders who fostered internal standards, greater accountability, promoted situated professional learning and reinforced the importance of connecting assessment judgements to teachers' day-to-day teaching engendered strong professional learning communities in their schools. Through collaboration on common work, teachers in these high schools developed new knowledge to improve their instruction and were strategic in bringing in expert knowledge from outside the school. They reflected on their practice, individually and together, and used evidence of student learning to design and evaluate interventions to address learning differentials amongst student groups. Through this process, teachers created shared language and standards for their practice, within and across subjects [12]. All of the practices described in these reviews [12], [22], [27] as effective in terms of promoting a school culture of teacher professional learning and development are relevant to the middle leader and department culture of secondary schools.

In the secondary school setting, the principal relies on the department leaders to provide the instructional advice and expertise required for effective leadership at department level. Reference [9] asserts that a great deal of the educational decision-making is being transferred to the department heads and[21] asserts that more research is needed on the reasons why school leaders at both senior and middle management levels choose to participate or not in teacher learning activities. Middle leaders have a role to play in modelling and encouraging senior leaders in the school to participate alongside themselves and their department colleagues in professional learning and development. Middle leaders who keep their school leader informed and involved in the professional learning decisions will empower everyone involved and are likely to make initiatives more sustainable.

The resource Leading from the Middle, developed by the NZ Ministry of Education [16]provides schools with a framework of understanding about the roles, responsibilities and dispositions of a middle leader and illustrates the earlier point about ways research is being made more accessible to leaders and teachers in schools so that they can apply theory to practice.

\subsection{Scoping PLD and Establishing PLD Goals}

Contract deliverables require the PLD provider to scope the PLD needs ofmiddle leaders and teachers (within the boundaries of the statement of work agreed to with the Ministry of Education) in order to provide a unique and strategic response to the school. After an initial meeting and the development of a memorandum of understanding between the school principal, the local ministry office and the PLD provider, the appointed coordinating facilitator for the school (a PLD facilitator with extensive experience) engages the school in discussions to help scope the PLD needs of middle leaders and identify in broad terms the aims of the PLD action plan.

To model (and mirror) the inquiry based approach expected at all levels of school organisation (from whole school self-review, through to classroom level teaching as inquiry), further scoping by a coordinating facilitator and subject specialist facilitators results in the development of a detailed PLD action plan.This approach is based on considerable evidence that even in very challenging situations leadership teams are able to transform their settings through engaging in evidence-informed collaborative inquiry [26]. This means a unique approach is taken, not a one-size-fits-all, although it is noted that the middle leader PLD needs that emerge in these schools contain common areas for development.

Data and evidence used to inform the action plan include (but are not limited to):

1. Student achievement data (essential):

- Disaggregated for Māori and Pasifika students, and also by gender, and where possible, students with special education needs were identified from the data;

- NCEA achievement data for levels 1-3, by level and by subject/learning area, NCEA level 1 literacy and numeracy, and University Entrance;

- Literacy and numeracy data for Year 9 and 10 students - the NZ developed asTTle literacy and numeracy assessments are the most popular measures;

- The level of expertise for managing achievement and other data on the school's student management system (SMS) is also checked. 
2. Analysis of the school charter, strategic goals and annual report (documentation required annually by the Ministry of Education and for schools reporting to their Board of Trustees).

3. An overview of school organisation and in particular, who the middle leaders are, their job descriptions, expectation, professional accountabilities, performance appraisal processes - as relevant to the school (noting that the organisational structure of small provincial or rural secondary schools is very different to large urban schools). Inevitably there is within-school variation [8] which is evidenced in the department data analysis. Further evidence and discussion may identify which learning areas have a higher priority, which helps the PLD provider and the school to make decisions together about how to allocate personnel and facilitation time to the school.

4. Analysis of recent government department reports specific to the school, eg the school's most recent:

- Education Review Office report (ERO is the New Zealand government office that reviews school performance);

- NCEA moderation report.

5. Social and cultural data as available, eg student voice (which if not available is included as part of the PLD process).

6. Identification of other school initiatives and existing PLD plans that have implications for the PLD provided through the SSA contract.

Further scoping conversations take place between the school curriculum middle leaders and the subject specific facilitators to identify specific aspects of leadership practices, related to the broader PLD goals that each middle leader will engage in. After school-wide and learning-area specific middle leader PLD needs are identified, a year-long PLD action plan is negotiated with the school which includes clear expectations of outcomes and the data that will be collected and reported at the conclusion of the PLD provision. These plans specify the learning areas and year levels of students that will be the main focus for the PLD and the middle leadership practices required to positively impact on identified priority students. Progress towards the goals detailed in the plan are formally monitored through regular team meetings with revisions made to the PLD plan as new evidence identifies the need to do so.

\subsection{Implementation of the PLD Plan}

Action plans are developed for all the allocated'indepth' schools, where there is intensive in-school PLD based on needs analysis and inquiry, focused on accelerating student achievement and where a team of leadership and subject experts facilitating PLD contain a combination of:

1. Generic middle leader practices, eg developing practice across the group of middle leaders (eg using data to track and monitor student progress and to inform programme planning and design decisions, developing aspects of NZC relevant pedagogy, including culturally responsive pedagogy); and

2. Subject-specific support for learning area/subject middle leaders to enhance their capacity to lead the learning of teachers in their department to improve aspects of teaching practice and raise student achievement.

Recurrent generic and learning area/subject specific PLD activities across schools facilitated by the PLD provider include development of:

- Systems and practices for identifying students at risk of not achieving at the expected level.

- Systems and practices for tracking and monitoring progress and achievement of students at risk of not achieving.

- The use of achievement (and social and cultural) data to inform learning programme design and planning.

- The understanding and application of inquiry based approaches, especially teaching as inquiry.

- Middle leaders' capacity to be leaders of learning (of teachers in their department), eg through running department meetings that focus on professional learning, conducting classroom observations and giving feedback to teachers about their practice (used as part of performance appraisal and documentation of teacher competence for registration purposes).

- Middle leaders' capacity to support each other professionally across the learning areas of the curriculum.

- Middle leader knowledge of their learning area in the NZC and planning programmes that reflect the NZC and meet the demands of NCEA at senior secondary level, and junior school programmes that prepare students for further learning at senior level.

- Developing disciplinary literacy for academic learning and NCEA achievement.

- Culturally responsive practice, eg using local contexts, changes to classroom pedagogy to focus more on interactive teaching strategies and discursive practice, knowing the learner through a range of data, using students' cultural worlds as a context for learning.

- The use of action plans to document departmental goals and intended achievement outcomes (or achievement targets) for students, and build capacity on how to use data and evidence to be strategic when deciding on PLD actions to achieve these improved outcomes for students.

\subsection{Reporting Evidence of PLD Impact}

The Ministry of Education, much like other social sector ministries, has in recent years adopted an intervention logic [2] approach for reporting ministry-led developments for the sector. The development of comprehensive rubrics describing developmental indicators of school performance (from ineffective to highly effective), underpin all PLD contract reporting. The implication of this intervention logic approach means that each PLD provider must collect evidence of improved middle leader practice and samples of achievement data to show that goals have been achieved and improved outcomes have occurred.

\section{Towards a Conceptual Framework for PLD in Secondary Schools}


It is clear from the foregoing description of the Secondary School Achievement PLD and its wider context, and the discussion of the research on effective schools and middle leaders, that developing a conceptual framework that responds to the complexities of PLD in the secondary school sector, is no simple task. In order to be relevant sector-wide, such a framework needs to take account of a diverse range of factors, some of them applicable across schools and some of them specific to individual schools or learning area departments.

Drawing on the experience of the SSA contract in engaging in PLD with middle leaders in secondary schools, a 'sandwich model' is proposed as a way to conceptualise PLD in schooling improvement initiatives. Given the potential for different layers and fillings, this model is able to accommodate a variety of factors influencing PLD programmes, whilst acknowledging the common structure (formed by government policy) within which the programmes operate. By changing 'fillings', the model can be adapted to suit particular PLD programmes. The food analogy is deliberate because it is about nurturing and feeding for growth and development. The choice of the sandwich is intended to be familiar to a wider global audience although the model could be adapted and more culturally responsive localised versions developed. The different layers of the sandwich are described below.

The 'bread': The bread represents the layers that maintain the integrity of the sandwich; as it forms the outer layers, the bread holds it together and gives the sandwich its overall shape and structure. These layers provide the (non-negotiable) structure for the conceptual framework. This structure includes the sector-specific educational policies and national strategies that must be complied with, the PLD contract deliverables and expectations, and the evidence that both informs the PLD plan and shows that expected outcomes have been met, policies adhered to and strategies responded to.

The 'spread' (the butter, mayonnaise, or other flavours): This permeates and enhances the flavour of all the other contents. In the case of SSA PLD, the spread is the inquiry-based principles for effective PLD mirroring the inquiry processes that are required across all school systems and practices.

The 'meat': The type of meat in the sandwich is usually what defines it and gives it its name. The 'meat in the sandwich' represents the central and fundamental purpose for schooling improvement which is about equitable outcomes for all students.

The 'fillings': The fillings may change depending on the overall flavour preferences or the specific aspect of the schooling improvement context that features in the PLD process. These fillings include:

- Understanding of research and evidence-based effective middle leader practice (which could adapt to senior leader or teacher practice); and

- Specific aspects of professional learning that the middle leader (or senior leader or teacher) needs to develop in order to become more effective in their practice.

Table 1. The 'Sandwich Model’ Illustrating The Conceptual Framework For Describing The Complexities of Professional Learning And Development Provision.

Top bread layer:

Current policies and strategies related to the secondary schooling sector (which in the New Zealand context include theNZC, Ka Hikitia, Pasifika Education Plan, Success for All, Better Public Service goals etc) and the ways these feature in government-funded contracts for PLD provision.

The spread:

Professional Learning and Development principles - inquiry and evidence based

The meat:

Social justice and equity considerations - equitable outcomes for all students, not only but especially priority learners.

The other fillings:

Theoretical and research-based best practice understandings of effective middle leadership practice (or senior leader or teacher practice)

Bottom bread layer:

Collection and use of a range of data to:identify the PLD needs of middle leaders (and teachers) and develop a strategic PLD plan of action; use as evidence to show how well schooling improvement outcomes have been achieved; identify other trends and issues emerging; and to inform next steps.

The 'sandwich model' conceptual framework in the delivery of in-service PLD for leaders and teachers summarised in the above table shows the range of factors that impact the scoping, provisioning and reporting of PLD in secondary schools. These factors need to be taken into account when carrying out research that seeks to inform practice in secondary schools, and when reporting on the effectiveness of a PLD programme. Without consideration of all of these factors, reporting on PLD processes and outcomes will not acknowledge the complexites of the PLD work.

\section{Recommendations}

If the rationale for developing a conceptual framework for understanding government-funded, externally provided professional learning development (PLD) illustrated through the 'sandwich model' is to make apparent the complex ways research evidence and policy come together in schools, what are the recommendations for policy makers and researchers?

\subsection{Recommendations for Policy Makers}

Concurrent with the writing of this paper, the New Zealand Ministry of Education is conducting a review of government funded professional development in New Zealand state schools[20].Policy advisors are able to investigate and use the evaluation of longer term projects, such as Secondary Student Achievement PLD, to inform future PLD policy and (re)design. This paper identifies some of the complexities of government funded PLD in the New Zealand context. The following recommendations are offered, based on the experiences of the provider of the SSA contract and as summarised from the major trends noted in contract reports. These considerations highlight the various aspects of the 
sandwich model as described in Table 1 and offer ideas for adding to existing knowledge in the field and adding to the existing literature both within New Zealand and internationally.

Key areas for consideration when designing and provisioning future secondary sector PLD:

- There are too many PLD interventions or projects in some schools, particularly in schools where there are many priority students, making a complex situation even more complex.

- Leaders need to be incentivised to take an evidencebased approach to prioritise the PLD interventions on the basis of student academic and social outcomes. School decisions about PLD are too often resourcedriven as opposed to being informed by evidence.

- When schools move from one PLD initiative to the next there is not always the opportunity (or established practice) to consolidate, embed, learn from, or build on previous PLD.

- Senior leader capacity for school self-review, coupled with the development of a culture of schoolwide inquiry to identify PLD needs, and a strategic response to these, remains a challenge in many schools.

- An observed lack of coherence between the school charter, annual (and strategic) plan, and related PLD plan, understanding of how learning-area specific PLD relates to these documents, as well as the way government policy and strategy should be incorporated in this planning, shows the gaps in some leaders' and teachers' understanding of the complexities of schooling improvement.

- The principles of KaHikitia [18] and the Pasifika Education Plan [19] are yet to be fully realised or embraced by school leaders and teachers, especially in relation to locating student success in identity, language and culture.

- The schooling improvement purposes of tracking and monitoring achievement of Māori, Pasifika and Special Education Needs students remains a challenge in order to locate the practice in realising learner potential instead of using data to support deficit theories [1]. Resistance from leaders and teachers is often encountered when the PLD process challenges them to have high expectations of all learners. School leaders and teachers need to understand and see examples of 'best practice' in this area, in order to accelerate improvement.

- All PLD interventions require robust research and evaluation integrated into the design that serves to inform the intervention and make adjustments to the programme and processes accordingly. The intervention needs to 'model' the robust evidence and inquiry methods required by school personnel.

\subsection{Recommendations for Secondary Sector and Researchers}

When PLD is government-funded and provided in response to government priorities and through policy and strategy, the outcomes need to meet the expected and required contract reporting conventions, and clearly report the shifts and changes at a student, teacher, leadership and whole school level. Without robust evaluation and reporting requirements, the outcomes are difficult to report in ways that are useful for the broader education sector. The causal link between the intervention in the school and student outcomes is particularly problematic in schools engaging in multiple interventions simultaneously. There are however opportunities to measure patterns and relationships between PLD intervention strategies and teacher and leader changes in practice. These practices need to be clearly described, identifable and observable by an external facilitator or researcher. Multiple measures are required to measure the shifts in leader and teacher professional behaviour and practice which can then be compared to student engagement and academic outcomes. Teacher learning must be connected to identified learner needs but often someone disconnected from the school makes decisions about what and how teachers are to learn [26] so evaluation of the outcomes is critical to inform the next steps in the PLD inquiry cycle.

Professional learning and development initiatives such as SSA have the potential to produce large quantitative data sets that can be established to identify broad patterns and relationships between intervention processes and outcomes for leaders, teachers and students. Qualitative case study research is also required to capture and value the localised outcomes from PLD providers, improved leader/teacher practice and individual student achievement that shows schools meeting achievement targets. Evidence informed practice that produces local school, department and classroom based evidence to keep informing the inquiry process is increasingly useful. Leaders and teachers who are engaged in the collaborative analysis of learner needs are motivated about new learning because there is a direct connection to their immediate context and impacting the equity outcomes for their learners.

\section{Acknowledgements}

This work is made possible by the team of highly skilled facilitators at The University of Auckland led by the contract's national director, Karl Mutch, and the officials at The Ministry of Education, who continue to respond, encourage and adapt to ensure the PLD contract can be optimised to the best effect for priority learners in New Zealand.

\section{Notes}

1. A full explanation of the National Certificate of Educational Achievement system can be found on the NCEA section of the New Zealand Qualifications Authority (NZQA) websitewww.nzqa.govt.nz. NZQA provide all schools with confidential rollbased data detailing NCEA achievement for students attending the school. Only broad overviews of these data are publicly available.

2. Literacy and numeracy assessment information is explained on the e-asTTle website http://easttle.tki.org.nz/.

3. New Zealand secondary schools have a choice of which student management system database (SMS) to purchase and use to manage their school data. The locally developed KAMAR system is proving to be 
the most popular for managing all of the data schools are expected to be able to access and use.

\section{References}

[1] Bishop, R., O'Sullivan, D., \& Berryman, M. (2010). Scaling up education reform: Addressing the politics of disparity. Wellington: NZCER Press.

[2] Davidson, E.J. (2005) Evaluation Methodology Basics: The Nuts and Bolts of Sound Evaluation. Thousand Oaks: Sage.

[3] Day, C., Sammons, P., Hopkins, D., Harris, A., Leithwood, K., Gu, Q., Brown, E., Ahtaridou, E., \& Kington, A. (2009) The Impact of School Leadership on Pupil Outcomes, DCSF Research Report London: Department for Children, Schools and Families.

[4] Dinham, S. (2007). The secondary Head of Department and the achievement of exceptional student outcomes. Journal of Educational Administration, 45(1), 62-79.

[5] Harris, A. (1998). Improving the effective department: Strategies for growth and development. Education Management and Administration, 26(3), 269-278.

[6] Harris, A., Jamieson, I. M., \& Russ, J. (1995). A Study of Effective Departments in Secondary Schools. School Organisation, 15(3), 283-300.

[7] Harris, A., \& Muijs, D. (2005). Improving Schools Through Teacher leadership, Maidenhead: Open University Press.

[8] Highfield, C. (2010). Disparity in student achievement within and across secondary schools: an analysis of department results in English, maths and science in New Zealand. School Leadership \& Management, 3(2), 171-190.

[9] Hofman, R. H., Hofman, W. H. A., \& Guldemond, H. (2001). The Effectiveness of Cohesive Schools. International Journal of Leadership in Education, 4(2), 115-135.

[10] Lee, V. E., Bryk, A. S., \& Smith, J. B. (1993). The Organization of Effective Secondary Schools. Review of Research in Education, 19, 171-267.

[11] Levin, B. (2008). How to change 5000 schools: A practical and positive approach for leading change at every level. Cambridge, Massachusetts: Harvard Education Press.

[12] McLaughlin, M., W, \& Talbert, J., E. (2007). Building professional learning communities in high schools: challenges and promising practices. In L. Stoll, \& L. Seashore, K (Eds.), Professional Learning Communities:Divergence, Depth and Dilemmas (pp. 151-165)Mardenhead, Berkshire: Open University Press.

[13] McNaughton, S., Robinson, V. M. J., \& Timperley, H. (2011). Building capacity in a self-managing school system. Journal of Educational Administration, 49(6),720-738.

[14] Ministry of Education (2007). The New Zealand Curriculum. Wellington: Learning Media Ltd.
[15] Ministry of Education (2011). Better Public Service Targets Retrieved11/11/2014from http://www.minedu.govt.nz/theministry/betterpublicservices.aspx.

[16] Ministry of Education (2012a). Leading from the middle: Educational leadership for middle and senior leaders. Wellington: Learning Media Ltd.Retrieved 29/01/2015 from http://www.educationalleaders.govt.nz/Leadership-

development/Key-leadership-documents/Leading-from-the-middle.

[17] Ministry of Education (2012b). Success for all, every school every child. Wellington: New Zealand Government.Retrieved 22/12/2014, from

http://www.minedu.govt.nz/NZEducation/EducationPolicies/Speci alEducation/OurWorkProgramme/SuccessForAll.aspx.

[18] Ministry of Education (2013a). Ka Hikitia Accelerating Success 2013-2017, the Maori Education Strategy. Wellington: New Zealand Government.Retrieved 11/11/2014 from http://www.minedu.govt.nz/theMinistry/PolicyAndStrategy/KaHik itia.aspx.

[19] Ministry of Education (2013b). Pasifika Education Plan 20132017. Wellington: New Zealand Government. Retrieved $11 / 11 / 2014$ from

http://www.minedu.govt.nz/NZEducation/EducationPolicies/Pasifi kaEducation/PasifikaEducationPlan2013.aspx.

[20] Ministry of Education, (2014). The report of the Professional Development Advisory Group. New Zealand Government. Retreived 22/12/2014 from

http://www.minedu.govt.nz/ /media/MinEdu/Files/TheMinistry/E ducationInitiatives/PLD/PLDAdvisoryGroupReport.pdf.

[21] Robinson, V. M. J. (2007). School leadership and student outcomes: Identifying what works and why. ACEL Monograph Series, 41, 27.

[22] Robinson, V. M. J., Hohepa, M., \& Lloyd, C. (2009). School leadership and student outcomes: Identifying what works and why, Best Evidence Synthesis.Wellington: Ministry of Education.

[23] Sammons, P., Hillman, J., \& Mortimore, P. (1995). Key Characteristics of Effective Schools: A Review of School Effectiveness Research. Institute of Education, University of London: London.

[24] Sammons, P., Thomas, S., \& Mortimore, P. (1997). Forging Links: Effective Schools and Effective Departments. London: Paul Chapman Publishing Ltd.

[25] Teachers Council, N. Z. (2009). Registered Teacher Criteria. Wellington: New Zealand Government.Retrieved 29/01/2015 from http://www.teacherscouncil.govt.nz/rtc.

[26] Timperley, H., Kaser, L., \& Halbert, J. (2014). A framework for transforming learning in schools: Innovation and the spiral, Seminar Series 234, Melbourne: Centre for Strategic Education.

[27] Timperley, H. S., Wilson, A., Barrar, H., \& Fung, I. (2007). Teacher Professional Learning and Development Best Evidence Synthesis. Wellington: Ministry of Education. 